Research Article

\title{
Minor Structures for the Improvement of Wave Disturbance in a Small Harbor
}

\author{
A. Sulis \\ Center of Environmental Sciences (CINSA), University of Cagliari, 09123 Cagliari, Italy \\ Correspondence should be addressed to A. Sulis; asulis@unica.it
}

Received 12 June 2018; Accepted 8 August 2018; Published 15 October 2018

Academic Editor: Hugo Rodrigues

Copyright (c) 2018 A. Sulis. This is an open access article distributed under the Creative Commons Attribution License, which permits unrestricted use, distribution, and reproduction in any medium, provided the original work is properly cited.

\begin{abstract}
A very important aspect in the planning, design, and maintenance of a harbor is to determine the response of the harbor basin to incident waves. The Saras harbor in South Sardinia (Italy) has been experiencing significant wave disturbance that affects the safety of mooring and operational activities. In the framework of a large research, this paper summarises a comprehensive description of new energy absorbing structures that can be seen as an efficient alternative to more traditional structures when limited by economic or technical constraints. Specifically, the paper presents the results of a graphical preliminary approach and a numerical modelling that solves the enhanced Boussinesq equations in two horizontal dimensions.
\end{abstract}

\section{Introduction}

Harbor tranquillity is an essential condition for safe anchorage and efficient port operation. Measuring the distribution of wave height in a given harbour layout should be related to the ship motion [1]. Here, we focus on the motion of service boats (tug, rescue boat, and coast guard) moored in water of finite depth and the viewpoint of maritime operation is not considered. Service boats remain within the harbor during all weather conditions and navigate at the harbour entrance particularly during severe storm conditions. Planning and design of harbor facilities should be based on an comprehensive understanding of the offshore wave modelled from an extreme wave analysis [2] and the estimation of the waves in the harbor for different layout configurations of breakwaters and other protective facilities. Facilities include energy dissipaters in the form of dentated and serrated blocks distributed on the vertical face of quay structures inside the harbor [3]. The amount of wave energy dissipation depends greatly on the slope provided. However, the milder the slope is the more expensive the structure is. In addition, mild slope may not be a technically feasible solution particularly in the case of upgrading of existing portrelated waterfront structures [4]. Serrated and dentated vertical quay structures are expected to hydrodynamically replace the mild slope structures from dissipating the incident wave energy and hence expected to reduce the wave reflection [5].

This paper presents a comprehensive application of graphical and numerical methods to the estimation of harbor tranquillity at the Saras harbor located on the southwest coast of Sardinia, Italy, where the Saras Group owns and operates integrated refinery and gasification plants. A refinery jetty extending $1.6 \mathrm{~km}$ into the Mediterranean was constructed to accept tankers of all sizes up to $300^{\prime} 000 \mathrm{DWT}$. The 10 berths of the jetty, which are about 10 miles south of the port of Cagliari, can take tankers with drafts of 20-39.6 ft. All crude for the refinery and petroleum products is transported by tanker. Service boats (tug, rescue boat, and coast guard) in the Saras harbor provide direct tanker assist service at the jetty. The main aim of the paper is to assess the improvement of harbor tranquillity at the Saras harbor when vertical dentated wall is designed in a large portion of the waterfront where a vertical plane wall exists. The manuscript is organized as follows. Section 2 describes the vertical dentated wall and its design in the Saras harbor. An extreme wave analysis from a 20 -year wave dataset is presented in Section 3. The problem of excessive wave disturbance at the 
Saras harbor was explored in both graphical and numerical models. In Section 4, a graphical method is applied for the estimation of wave height distribution in the harbor. Section 5 shows the application of a Boussinesq numerical model and a comparison of results with the graphical method is presented. The final section gives some suggestions for future developments.

\section{Wave Absorbing Structures}

The hydrodynamic performance of rough structures has been investigated in previous physical and numerical model studies (e.g., [6-9]), considering a wide range of waves, both regular and irregular, and level conditions. It is found that the investigation of $[3,5]$ on wave reflection from a dentated and serrated sloped seawall is a unicum in the literature. The physical modelling results have confirmed that the introduction of a number of rectangular blocks in the form of dents or serrations on a plane vertical seawall hydrodynamically replaces the mild sloped seawall from dissipating the incident wave energy and hence reduces the wave reflection. Specifically, they investigated the effect of wave height (in terms of wave steepness, $H_{s} / L_{\mathrm{p}}$, being $H_{\mathrm{s}}$ the significant wave and $L_{\mathrm{p}}$ the wavelength corresponding to the peak period), wave period (in terms of relative water depth, $\left.\mathrm{d} / L_{\mathrm{p}}\right)$, and surf similarity parameter $(\xi)$ on the reflection coefficient $\left(K_{\mathrm{r}}\right)$. The coefficient of wave reflection $K_{\mathrm{r}}$ is defined as the ration of reflected wave height $H_{\mathrm{r}}$ to incident wave height $H_{i}$. Here, both the incident and reflected wave heights refer to the significant heights. Due to the higher energy dissipation, $K_{\mathrm{r}}$ values decrease significantly with decrease of the seawall slope for steeper waves either in the case of plane, dentated, or serrated walls. Here, we focus on the results on random waves acting on vertical seawalls. The effect of seawall type on the reflection coefficient $K_{\mathrm{r}}$ for different peak wave periods is provided in Figure 1. For $d / L_{\mathrm{p}}$ $=0.09$ (long wave), the reflection characteristics of all three types of seawall are almost the same. For $d / L_{\mathrm{p}}>0.09$, compared to plane and serrated seawall, dentated seawall assures a significant reduction for a large range of $d / L_{\mathrm{p}}>$ 0.09 , while the performance of dentated and serrated is almost similar for $d / L_{\mathrm{p}}=0.45$. In addition, Neelamani and Sandhya [5] proposed predictive equations for the reflection coefficient $K_{\mathrm{r}}$ for regular and irregular waves, vertical and sloped walls, and plane, dentated, and serrated walls. Here, the predictive equation for vertical dentated wall with random waves is shown below:

$$
K_{\mathrm{r}}=\frac{d / L_{\mathrm{p}}}{1.5\left(d / L_{\mathrm{p}}\right)-0,03}, \quad 0.09<\frac{d}{L_{\mathrm{p}}}<0.45 .
$$

Goda [1] reports approximate values of reflection coefficients from various sources (Table 1). The range in the coefficient for a vertical wall depends on the degree of wave overtopping.

Along the problem of energy dissipation, harbour tranquillity is related to the estimation of the propagation of the reflected waves. Based on the theory of geometrical optics, each component of a random sea is assumed to be

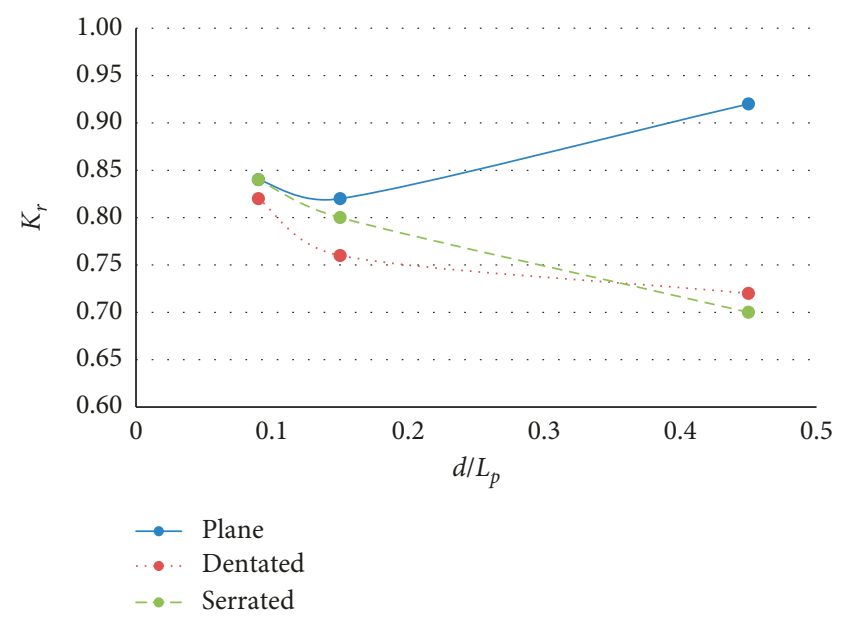

FIgURE 1: Comparison of the reflection coefficient $K_{\mathrm{r}}$ for plane, dentated, and serrated vertical seawalls. Different periods are shown corresponding to $d / L_{\mathrm{p}}=0.09 ; 0.15 ; 0.45$ and $H_{\mathrm{s}} / d=0.14$. (adapted from [5]).

TABLE 1: Approximate value of reflection coefficients [1].

\begin{tabular}{lc}
\hline Structural type & $K_{\mathrm{r}}$ \\
\hline Vertical wall with crown above water & $0.7 \sim 1.0$ \\
Slope of rubble stones & $0.3 \sim 0.6$ \\
Vertical structure of energy dissipating type & $0.3 \sim 0.8$ \\
Natural beach & $0.05 \sim 0.2$ \\
\hline
\end{tabular}

reflected at an angle equal to the angle of incidence and to continue to propagate in that direction. An exception is due to the phenomenon called Mach-stem reflection [10, 11]. Having reflected waves a finite length along their crest lines, reflected waves disperse during propagation away from the source of reflection in a manner similar to the phenomenon of wave diffraction. Goda [1] proposed an engineering approximation of the spatial distribution of reflected wave height by making use of diffraction diagrams of random sea waves for an opening between breakwaters. This allows properly taking into account directional spectral characteristics in $2 \mathrm{D}$ propagation of sea waves. Then the effect of reflected waves on the harbor agitation can be estimated in terms of wave heights by the principle of summation of energy component as in the following:

$$
H_{T}=\sqrt{H_{i}^{2}+\left(H_{r}\right)_{1}^{2}+\left(H_{r}\right)_{2}^{2}+\ldots}
$$

where $H_{T}$ denotes the significant height of the superposed waves and $\left(H_{\mathrm{r}}\right)_{1},\left(H_{\mathrm{r}}\right)_{2}, \ldots$ represent the significant heights of the waves reflected at various structures. Specifically, Equation (2) is applicable at a distance from the reflective structure more than one wavelength.

2.1. Saras Harbor Case Study. The Saras harbor is located in the Gulf of Cagliari on the south-west coast of Sardinia at a latitude $39^{\circ} 4^{\prime} 57^{\prime \prime} \mathrm{N}$ and longitude $9^{\circ} 1^{\prime} 21^{\prime \prime} \mathrm{E}$ (Figure 2). The harbor protection is achieved by the construction of two main shore-connected rubble-mound breakwaters (moles 


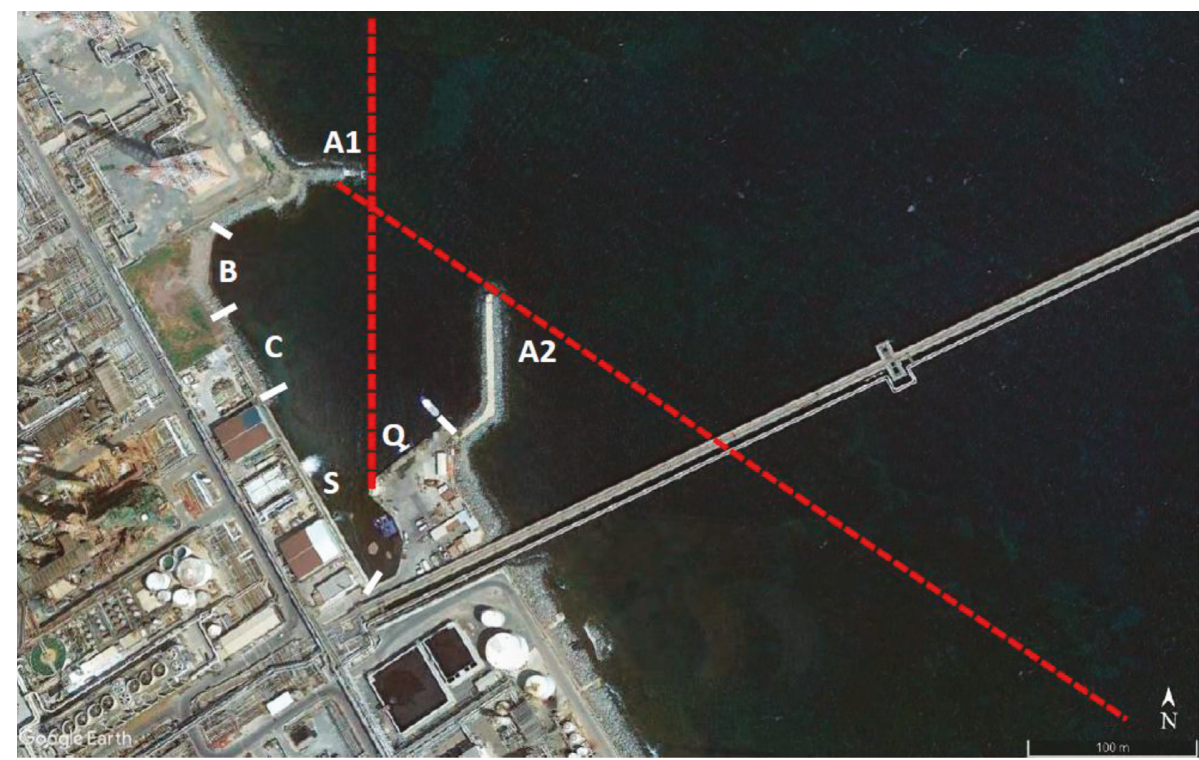

FIGURE 2: Saras harbor layout (in addition to the text: B: sandy beach; C: rocky revetment; red dotted lines define the portion of the waterfront from where the outer sea can be viewed through the harbor entrance).

$\mathrm{A} 1$ and $\mathrm{A} 2$ in Figure 2) with one layer of armor quarry rocks. Waterfront structures have a complex layout and are composed of seawall (S) and quaywall (Q) (with a berthing face for boats) both of gravity, vertical and impermeable structure types. Unfortunately, the basin confined by the structures does not provide safe and efficient port operation due to wave disturbance. As suitable berthing conditions are not provided, minor structural modifications of waterfront structures should be considered. At this time, major modifications as a new harbor layout cannot be proposed for economic and authorization constraints. The pattern of wave propagation into the harbour basin is mainly governed by diffraction and reflection.

The proposed design for the improvement of the Saras harbor tranquillity was to provide with wave-absorbing revetments. Specifically in the portion of the waterfront from where the outer sea can be viewed, the vertical plane seawall will be covered by a dentated structure of marinegrade stainless steel (Figure 3). Being the entrance too wide, as can be seen in Figure 2, the outer sea can be viewed from every basin location through the harbor entrance. Then, the design incoming waves are assumed those that would have arrived in the same locations in the absence of the harbor. Specifically, incoming waves with mean wave direction at the harbour entrance between $0^{\circ} \mathrm{N}$ and $120^{\circ} \mathrm{N}$ are simulated in the following.

\section{Wave Analysis: Extreme and Ordinary Climate}

Wave data from this analysis come from the buoy data provided by the Italian buoy network RON (Rete Ondametrica Nazionale, Italy). Along the Italian coasts, RON includes 15

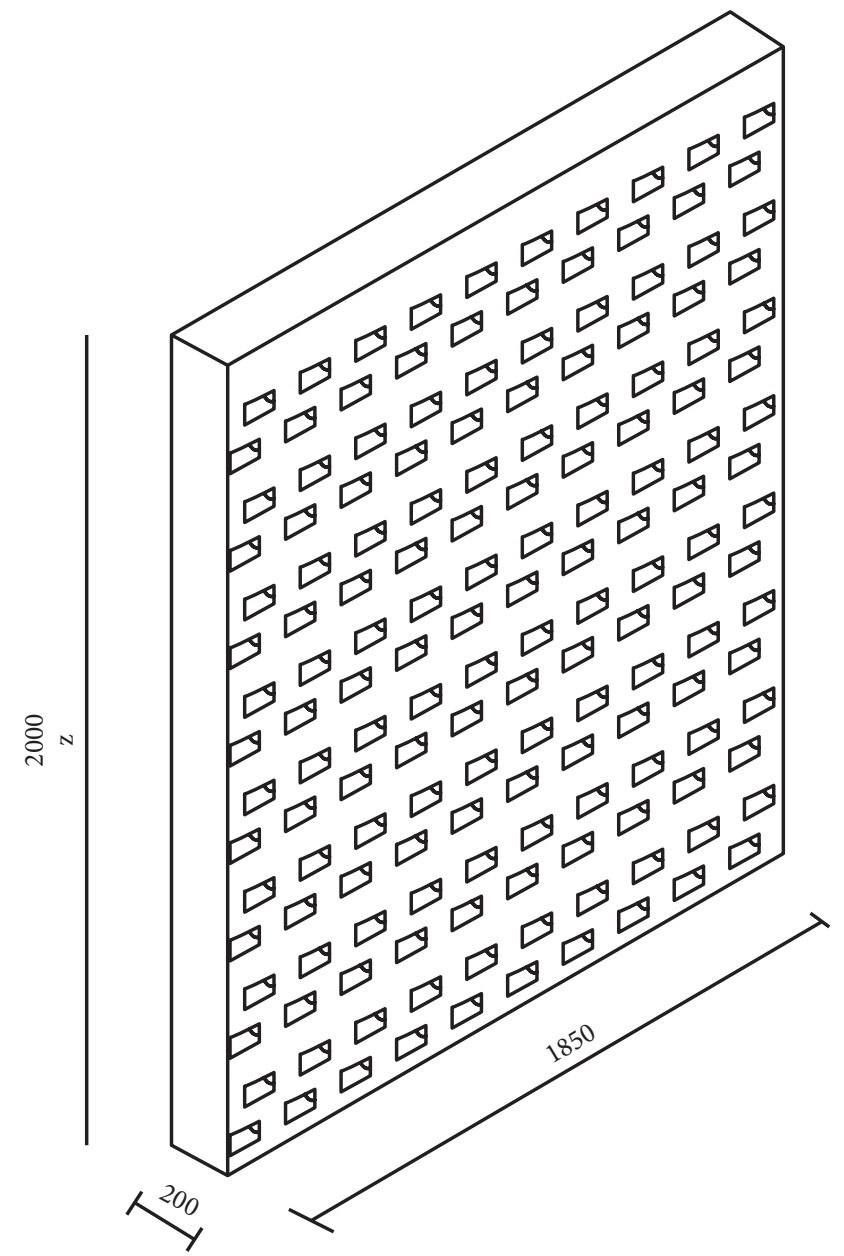

FIGURE 3: Isometric view of the dentated seawall (adapted from [5]). 

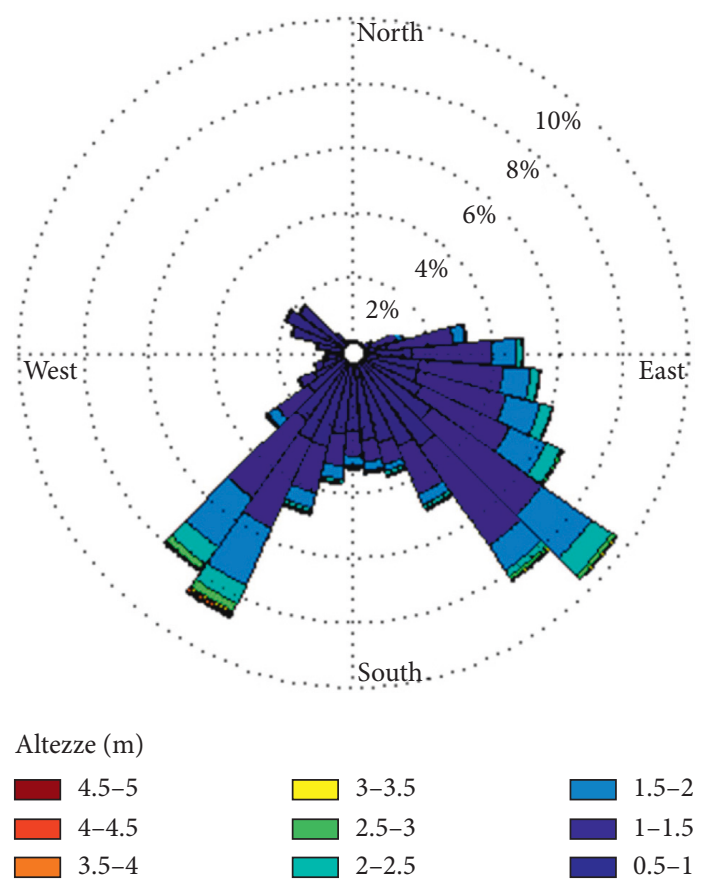

Figure 4: Rose chart of significant wave height at the Cagliari buoy.

directional wave buoys collecting 20-minute series of wave and meteorological parameters every 30 minutes. Significant wave height, peak period, and mean direction were used in this study from December 15, 2009 to December 31, 2014 collected from the Watchkeeper buoy with particle-following sensor technology deployed at a latitude $39^{\circ} 06^{\prime} 54^{\prime \prime} \mathrm{N}$ and longitude $9^{\circ} 24^{\prime} 18^{\prime \prime} \mathrm{E}$. In Figure 4, a rose chart of significant wave heights illustrates the percentage of wave measurements coming from different directions. The rose shows that two main directions are consistently predominant in magnitude and frequency: $170-180^{\circ} \mathrm{N}(\%)$ and $260-270^{\circ} \mathrm{N}$ (\%), corresponding to the Scirocco (southeast wind) and Libeccio (southwest wind) winds in the Mediterranean Sea, respectively.

The extreme wave analysis (EWA) was performed on sea store values. Following Boccotti [12], a sea storm as "a sequence of sea states in which the significant wave height $H_{\mathrm{s}}$ exceeds the threshold $H_{\text {crit }}$ and does not fall below this threshold for a continuous time interval greater than 12 hours" is defined in this study. Regarding $H_{\text {crit }}$, it depends upon the given location. For enclosed seas in the Mediterranean Sea, Sulis et al. [2] considered an $H_{\text {crit }}$ equal to $2.0 \mathrm{~m}$. Each storm was represented by its peak wave height during the storm. The wave dataset was composed of 53 wave heights (Figure 5). For maritime design, Goda's peak over threshold method [1] is one of the main stable models applied to extreme wave analysis $[13,14]$ and the techniques for EWA were applied for the use of POT values. POT takes in account for the adoption of a second censoring threshold (censoring parameter $v$ ) in order to achieve the highest stochastic independence and homogeneity possible between the samples. As $v$ value selection is critical [15], a sensitive analysis was performed, and $v=1$ was selected giving a large data.

Previous research [2] performed a detailed analysis of extreme wave height estimates by making use of different cumulative distribution functions (Gumbel, FisherTippett type 2, Weibull, and Generalized Pareto) and fitting methods (least squares method, the method of L-moments, the maximum likelihood method, and the method of moments). The correlation coefficient was used as degree of goodness to fit in order to assign the "optimal" distribution parameter values that best fit the dataset for each distribution function and best-fitting method; then the probability plot correlation coefficient values were used to compare goodness-of-fit test among distribution functions that passed the Chi-square test. Sulis et al. [2] demonstrated that the least squares method is the best for the Gulf of Cagliari in terms of unbiasedness and efficiency, and the GPD and Weibull are generally better than Gumbel and FT-II. In the following, the application of Weibull distribution fitted with the least squares method is presented:

$$
f(H)=\frac{k}{A}\left(\frac{H-B}{A}\right)^{k-1} \exp \left[-\left(\frac{H-B}{A}\right)^{k}\right],
$$

with the shape parameter $k=1$, the scale parameter $A=0.77$ and the location parameter $B=1.33$. The fitted Weibull distribution in Equation (3) was used to estimate wave height quantiles for return periods of 2, 5, 10, 20, 50, and 100 years (Figure 6). Specifically, the wave heights $H_{\mathrm{st}}$ estimated for 2- and 5-year return periods are equal to $3.85 \mathrm{~m}$ and $4.56 \mathrm{~m}$. To consider the effects of the selected structure over different wave periods, two wave scenarios were constructed with mean periods $T_{0}=4$ and 9 seconds. 


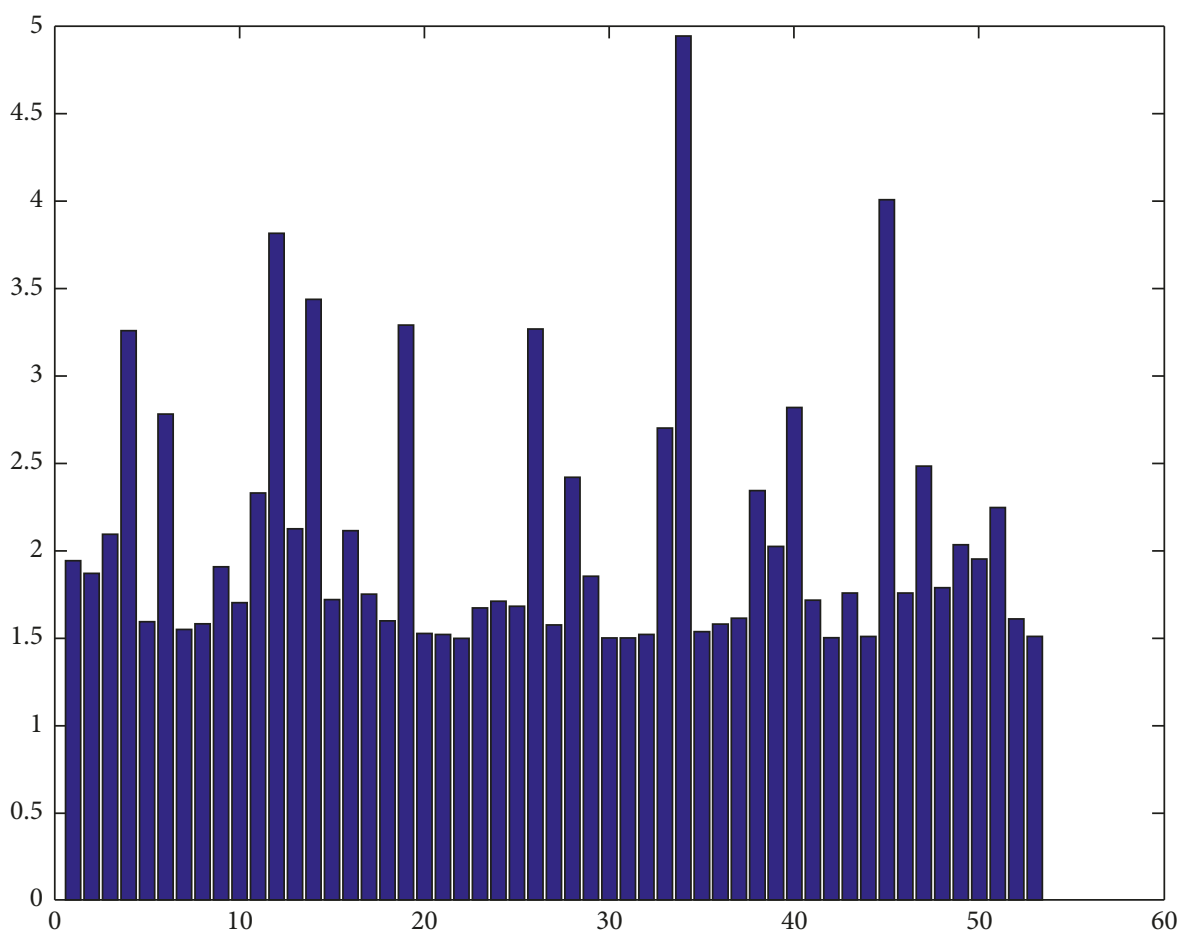

FigURE 5: Wave dataset composed of 53 peak wave heights (in terms of significant height $H_{\mathrm{s}}$ ) of storms in the period 2009-2014 measured at the RON buoy.

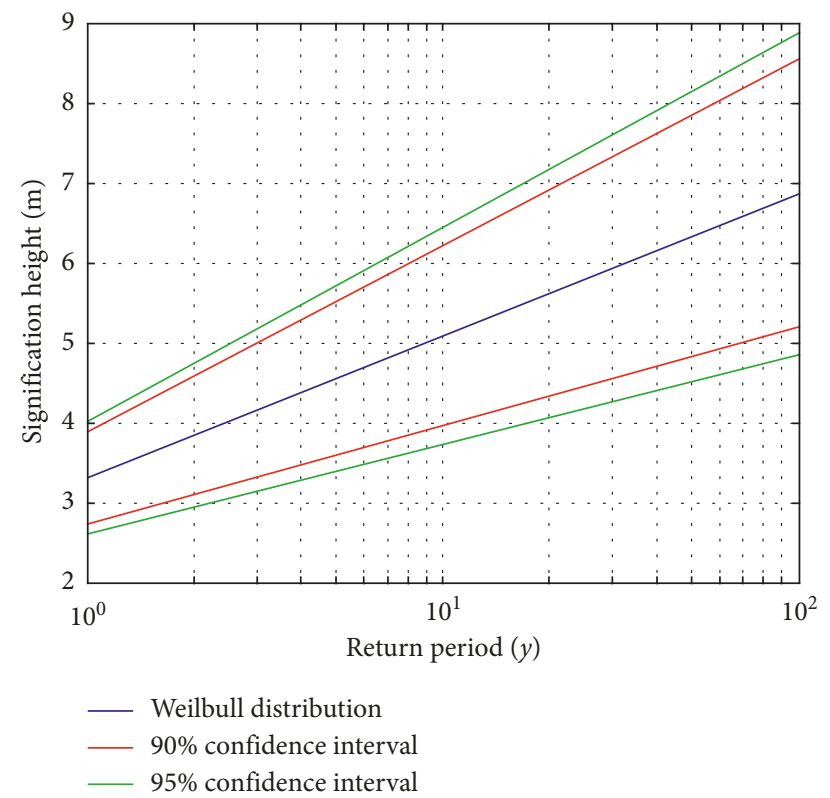

Figure 6: Return level estimation with Weibull distribution (Equation (1)) and confidence intervals.

\section{Application of a Graphical Method}

The selected wave conditions are summarised in Table 2. Specifically, three incoming waves were considered with mean wave direction $M W D=0^{\circ} \mathrm{N}, 90^{\circ} \mathrm{N}$, and $120^{\circ} \mathrm{N}$ at the
TABLE 2: EWA statistics.

\begin{tabular}{lcc}
\hline$H_{\mathrm{s}}(\mathrm{m})$ & $T_{0}(\mathrm{~s})$ & $\mathrm{MWD}\left({ }^{\circ} \mathrm{N}\right)$ \\
\hline 3.85 & 4 & 0 \\
4.56 & 9 & 0 \\
\hline
\end{tabular}




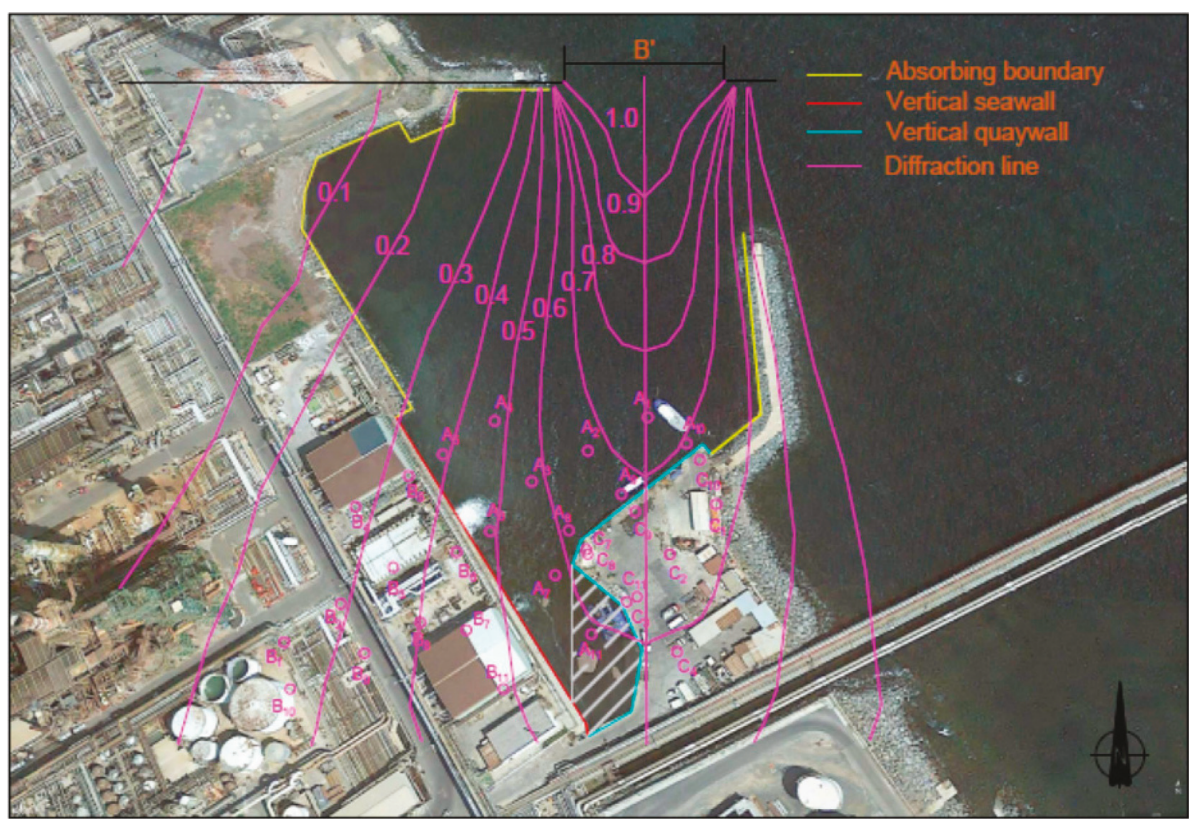

Figure 7: Mirror-imaged diffraction diagram at the Saras harbor considering a mean direction incident wave of $0^{\circ} \mathrm{N}$.

TABLE 3: Superimposition of diffracted and reflected wave heights (location points is shown in Figure 7).

\begin{tabular}{|c|c|c|c|c|c|c|c|c|}
\hline \multirow{2}{*}{ Point } & \multirow{2}{*}{ Zone A } & \multirow{2}{*}{ Zone B } & \multirow{2}{*}{ Zone C } & \multicolumn{3}{|c|}{ Ratio of superimposed wave } & \multirow{2}{*}{$(\mathrm{A}-\mathrm{B}) / \mathrm{A}$} & \multirow{2}{*}{$(\mathrm{A}-\mathrm{C}) / \mathrm{A}$} \\
\hline & & & & Case A & Case B & Case C & & \\
\hline $\mathrm{A} 1$ & 0.74 & 0.26 & 0.62 & 1.00 & 0.88 & 0.91 & $12 \%$ & $9 \%$ \\
\hline $\mathrm{A} 2$ & 0.68 & 0.29 & 0.64 & 0.98 & 0.84 & 0.88 & $14 \%$ & $10 \%$ \\
\hline A3 & 0.58 & 0.25 & 0.62 & 0.89 & 0.75 & 0.79 & $16 \%$ & $11 \%$ \\
\hline A4 & 0.48 & 0.28 & 0.58 & 0.80 & 0.66 & 0.70 & $18 \%$ & $12 \%$ \\
\hline A5 & 0.39 & 0.34 & 0 & 0.52 & 0.46 & 0.48 & $12 \%$ & $8 \%$ \\
\hline A6 & 0.49 & 0.44 & 0 & 0.66 & 0.58 & 0.60 & $12 \%$ & $8 \%$ \\
\hline A7 & 0.54 & 0.46 & 0.62 & 0.94 & 0.76 & 0.82 & $19 \%$ & $13 \%$ \\
\hline A8 & 0.61 & 0.4 & 0.61 & 0.95 & 0.80 & 0.84 & $16 \%$ & $11 \%$ \\
\hline A9 & 0.68 & 0.34 & 0.66 & 1.01 & 0.86 & 0.90 & $15 \%$ & $10 \%$ \\
\hline A10 & 0.69 & 0.27 & 0.69 & 1.01 & 0.86 & 0.91 & $15 \%$ & $10 \%$ \\
\hline A11 & 0 & 0.49 & 0 & 0.49 & 0.34 & 0.39 & $30 \%$ & $20 \%$ \\
\hline
\end{tabular}

harbor entrance in order to be representative of the all possible directions $\left(0-120^{\circ} \mathrm{N}\right)$. Considering a water depth $h=$ $6.5 \mathrm{~m}$ at mean higher high water level, wavelengths at the harbor entrance are $L_{\mathrm{p}} \approx 24$ and $68 \mathrm{~m}$ and the apparent opening width of the entrance from the wave direction of $M W D=0^{\circ} \mathrm{N}$ is $B^{\prime} \approx 70 \mathrm{~m}$, thus the relative width $B^{\prime} / L_{\mathrm{p}} \approx 2.9$ and 1.0. In the following, the paper focuses on the $M W D=$ $0^{\circ} \mathrm{N}$ that produces the worst case of wave disturbance. A preliminary analysis was carried out with a graphical method called the mirror-imaged diffraction method $[1,16]$. The method uses diffraction diagrams for random sea waves [1], transfers the geometry of harbor layout in the plane by a mirror image along the boundary of wave reflection, and examines the reflected waves as waves travelling in the mirror-image plane. Goda [1] presented several examples of the method application and the reader is referred to this textbook for an exhaustive presentation. Points $A_{j}(j=1,2$, $\ldots, 11)$ are the locations at which the wave height is to be estimated (Figure 7 ). Being $B^{\prime} / L_{\mathrm{p}} \approx 2.9$, for $s_{\max }=75$, the random wave diffraction diagram is given by [1] at page 85 .
It is to be noticed that the application slightly underestimates the disturbance phenomenon as the secondary wave reflections are omitted. The resultant wave height at each of the eleven points is estimated using the principle of summation of wave energy of Equation (2) where the reflected wave heights $\left(H_{\mathrm{r}}\right)_{1},\left(H_{\mathrm{r}}\right)_{2}, \ldots$ are those calculated in the plane of the two mirror images (Zone $\mathrm{B}$ and Zone $\mathrm{C}$ ) with the vertical seawall and quaywall as reflective structures. When the absorbing structures are considered, the diffraction coefficients in Zone $\mathrm{B}$ and Zone $\mathrm{C}$ are reduced by a rate equal to the reflection coefficient. Table 3 shows three different cases in the estimation of superimposed waves: Case A is the current configuration with vertical reflective structures and Case B and Case $\mathrm{C}$ are related to the design of dentated vertical seawalls in place of the existing seawall and quaywall for incident waves with $T_{0}=4$ and 9 seconds, respectively. Using Figure 1, it can be seen that the reflection coefficient $K_{\mathrm{r}}$ for $T_{0}=4$ and 9 seconds is equal to 0.7 and 0.8. Comparing Case A with Case B and Case $\mathrm{C}$ gives useful preliminary information to harbor managers and designers on the improvement in wave 


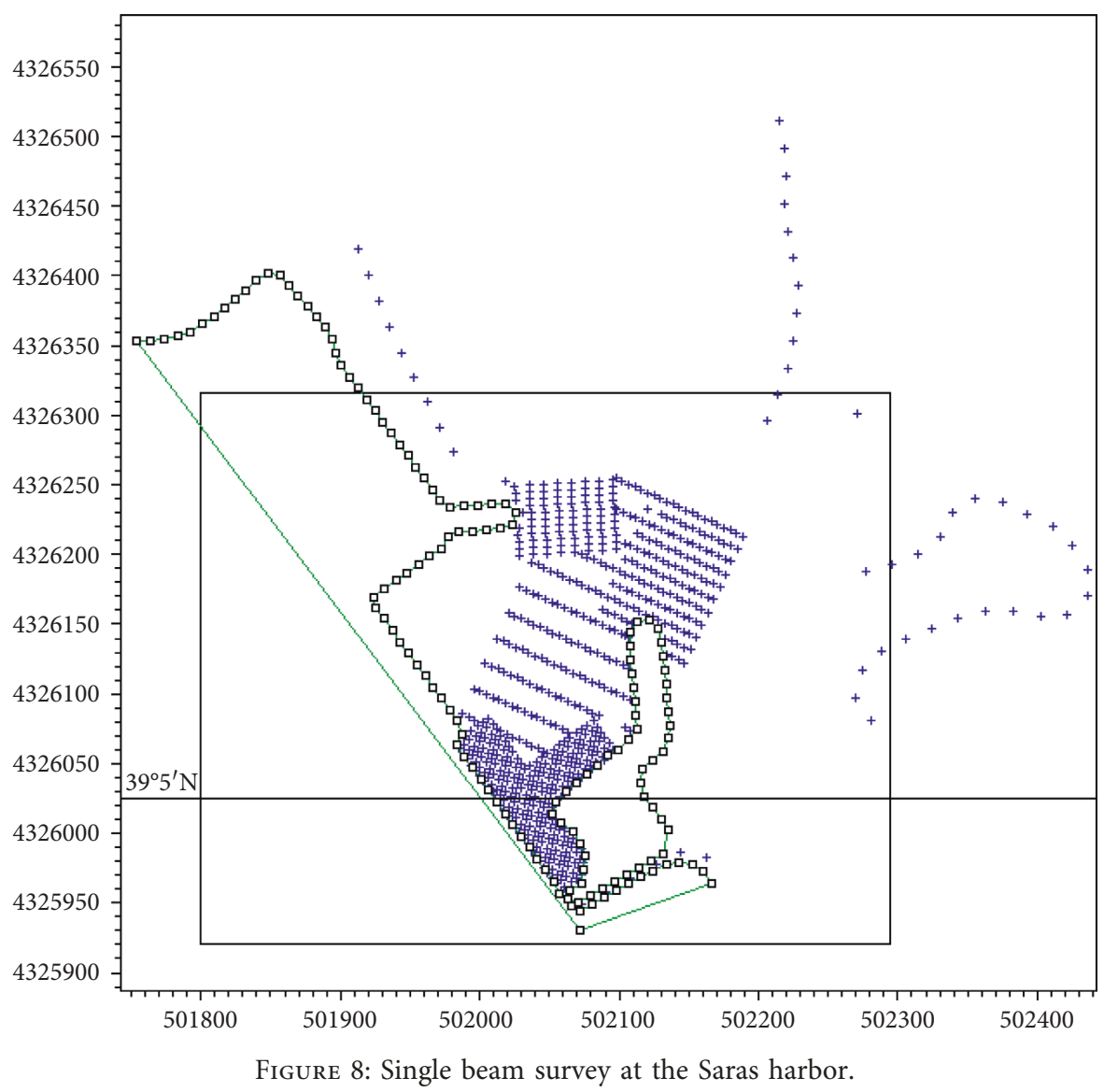

disturbance that the construction of these energy dissipating vertical structures can produce. Considering the wider harbor area with eleven points, it can be noticed that the improvement can assume values in a wide range, from $8 \%$ to $30 \%$. Specifically, considering the mooring points $\left(A_{7}, A_{8}, A_{9}, A_{10}\right.$, and $\left.A_{11}\right)$, the improvement is higher in the shadow zone $\left(A_{10}\right.$ and $A_{11}$ ), while points $A_{7}, A_{8}$, and $A_{9}$ are mainly interested by incident waves coming from the wide harbor entrance, and the reflected components are less significant. In the latter, a lower reflection coefficient in the designed absorbing structures will not significantly improve the wave disturbance. As expected, dentated structures have a higher performance in reducing the wave disturbance in the case of incoming random sea waves with higher $d / L_{\mathrm{p}}$ values. In particular, Case $\mathrm{B}$ and Case $\mathrm{C}$ are related to $d / L_{\mathrm{p}}=0.27$ and 0.10 . In the mooring points $\left(A_{7}, A_{8}, A_{9}, A_{10}\right.$, and $\left.A_{11}\right)$, the energy dissipation for shorter waves is always higher than $15 \%$. From this preliminary graphical approach, the results confirmed that designed energy absorbing structures are efficient in shadow area of the harbor hit by short storm waves of $T_{0}=4$. For longer waves $\left(T_{0}>9\right.$ seconds), the improvement cannot be very significant.

\section{Application to a Numerical Method}

The deepwater waves from the EWA with the statistics of Table 2 were transformed to shallow water using nearshore spectral wind-wave (NSW) model of DHI [17]. NWS is a stationary, directionally decoupled, parametric model which describes the propagation and decay of short period and short crested waves in nearshore areas. Sulis and Annis [18] provide details of the nearshore wave transformation. A detailed bathymetric model at the entrance and in the inner harbor was generated using a single-beam echo-sounder (Figure 8). For examining the inner harbor wave propagation in a good trade-off between computational times, and accuracy and stability, a bathymetry with a grid resolution of $4 \mathrm{~m} \times 4 \mathrm{~m}$ was chosen. A model area covered approximately $120 \mathrm{~m} \times 120 \mathrm{~m}$ and was rotated of $35^{\circ}$ in such a way that the offshore boundary is parallel to the deepwater contours (Figure 9). This wave and bathymetric configuration was used to assess wave disturbance into the Saras harbor using Boussinesq wave (BW) model of DHI [19]. The BW model solves the enhanced Boussinesq expressed in two horizontal dimensions [20] in terms of the free surface elevation, $\xi$ and the depth-integrated velocity-components, along $x$-axis (P) and $y$-axis (Q). Boussinesq equations are solved by implicit finite difference techniques and the convective terms are discretised using central differences and the normal ADI algorithm for numerical integration. Partial reflection from revetment, vertical seawall, and quaywall were included in the simulations by specifying porosity values corresponding to reflection characteristics of the specified structures. Wave height and ratio of superimposed waves were simulated for different combinations 


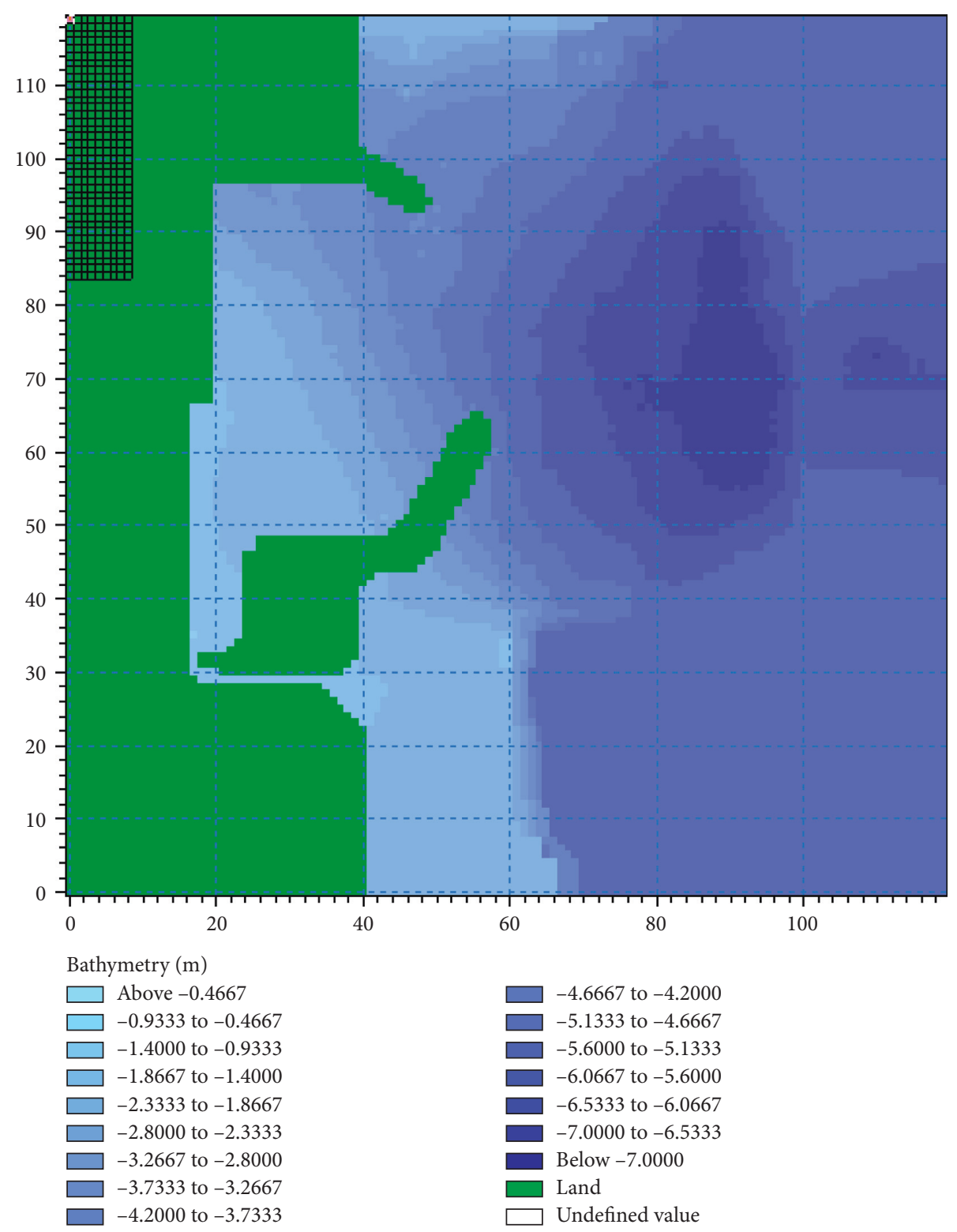

Figure 9: Bathymetry at the Saras harbor.

of incident wave heights, periods, and directions as reported in Table 2. In the following, the paper summaries on the worst condition of a $M W D=0^{\circ} \mathrm{N}$ that produces the most significant wave penetration into the harbor. Considering the Saras harbor orientation with respect to the Cagliari Gulf, a wave of $T_{0}=4$ and $H_{\mathrm{st}}=3.85 \mathrm{~m}$ was chosen for $M W D=0^{\circ} \mathrm{N}$. Two structural configurations were simulated: the current configuration with vertical impermeable seawall (Conf 1 ) and quaywall and the configuration with the dentated structures (Conf 2). The maps of wave disturbance coefficient for both simulations are reported in Figure 10 for an immediate visual comparison. It is evident, also by a qualitative point of view, that the introduction of energy dissipating structures in forms of dentated vertical structures significantly reduces the disturbance of superimposed waves specifically in the mooring area where Conf 1 does not allow service boats for an essential condition for safe anchorage and efficient port operation. In the mooring area, the incoming waves are significantly amplified through reflection at the quaywall reaching coefficient values higher than 0.7 (orange and red values in the legend). Conf 2 will assure lower wave disturbance with the coefficient in the mooring area always lower than 0.6. Considering the $A_{2}$ point where the maximum superimposition was simulated by the BW model, the maximum wave height $H_{\max }$ in the current configuration Conf 1 was equal to $95.5 \mathrm{~cm}$, while in the designed configuration Conf 2 results show $H_{\max }=65.1 \mathrm{~cm}$ with an improvement in wave disturbance higher than $31 \%$.

\section{Conclusions}

This paper summarizes a large research in the field of wave disturbance applied to the Saras harbor located in South 


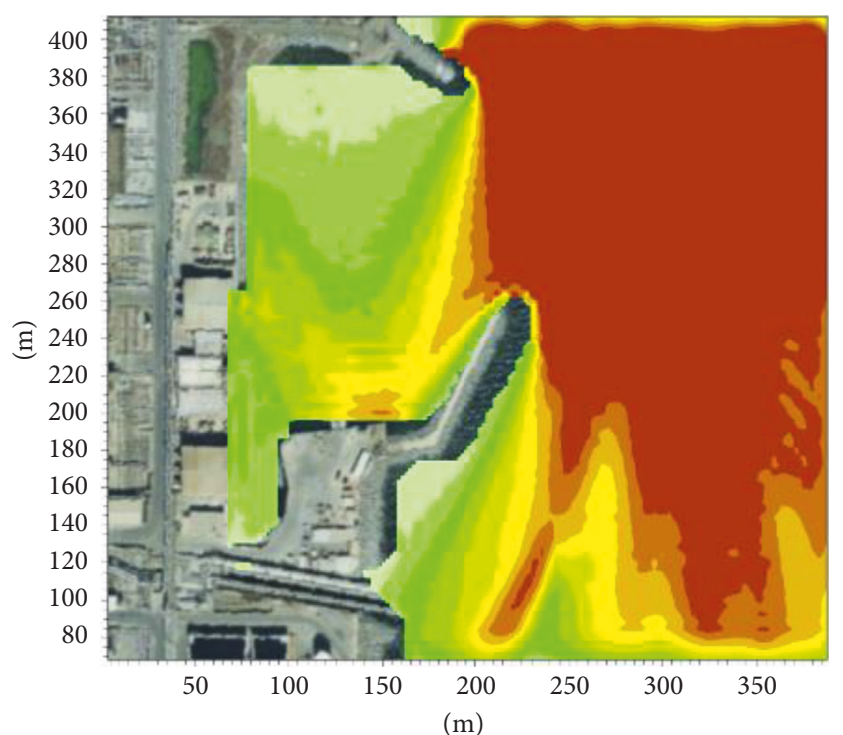

Hm0/Hm0_incoming

(0)

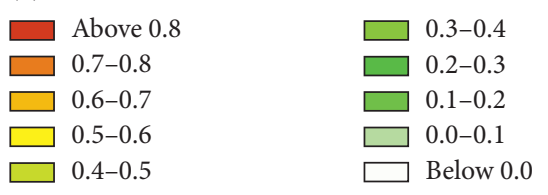

(a)

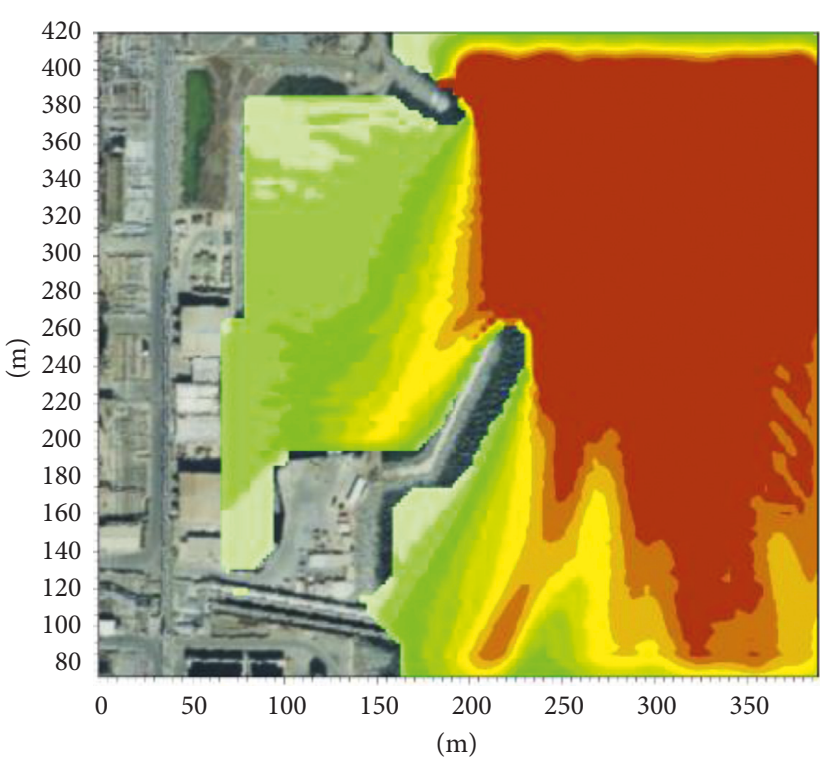

Hm0/Hm0_incoming

(0)

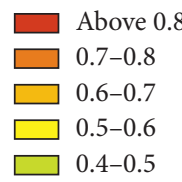

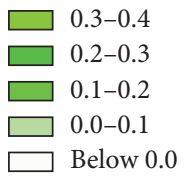

(b)

Figure 10: Wave disturbance coefficient for MWD $=0^{\circ} \mathrm{N}, T_{0}=4$, and $H_{s t}=3.85 \mathrm{~m}$ in the current configuration (a) and designed configuration with dentated structures (b).

Sardinia (Italy) where the current harbor configuration does not assure safe operational conditions. Due to technical restrictions, traditional wave absorber cells cannot be realized and new, experimental approach should be considered. Among these approaches, the dentated and serrated vertical seawalls appear to give the possibility of reducing the high wave disturbance particularly for short wave. A graphical method and a Boussinesq numerical method were applied to simulate the degree of the improvement when the designed new structures are constructed. While the graphical approach gives an approximated solution, it can be seen as a preliminary step in the structure design when no detailed information on bathymetry or additional forces (e.g., wind and tides) are available. When these additional forces become available, more accurate numerical methods (e.g., [21]) can be used also provided by well-known commercial software. In this paper, the application of a Boussinesq wave model is presented. The results suggest that the dentated structural solution can assure safer condition for service boats in the Saras harbor. In addition, the comparison between the graphical and numerical models shows that the latter simulates a significantly higher improvement in the all mooring area.

\section{Data Availability}

Data are public (e.g., wave data).

\section{Conflicts of Interest}

The author declares that there are no conflicts of interest regarding the publication of this paper.

\section{References}

[1] Y. Goda, Random Seas and Design of Maritime Structures, Advanced Series on Ocean Engineering, Vol. 33. World Scientific Publishing, Singapore, 3 edition, 2010.

[2] A. Sulis, R. Cozza, and A. Annis, "Extreme wave analysis methods in the Gulf of Cagliari (South Sardinia, Italy)," Ocean and Coastal Management, vol. 140, pp. 79-87, 2017.

[3] S. Neelamani and N. Sandhya, "Surface roughness effect of vertical and sloped seawalls in incident random wave fields," Ocean Engineering, vol. 32, pp. 395-416, 2005.

[4] G. P. Tsinker, "Repair, rehabilitation, maintenance, and upgrading of waterfront structures, 6th chapter," in Port Engineering. Planning, Construction, Maintenance, and Security, G. P. Tsinker, Ed., John Wiley \& Sons, Inc., Hoboken, NJ, USA, 2004.

[5] S. Neelamani and N. Sandhya, "Wave reflection characteristics of plane, dentated and serrated seawalls," Ocean Engineering, vol. 30, no. 12, pp. 1507-1533, 2003.

[6] N. W. H. Allsop and A. R. Channell, "Wave reflections in harbours," Report OD 102, Hydraulics Research, Wallingford, UK, 1989.

[7] C. Altomare, A. J. C. Crespo, J. M. Domínquez, M. GómezGesteira, T. Suzuki, and T. Verwaest, Coastal Engineering, vol. 96, pp. 1-12, 2015. 
[8] P. A. Madsen, "Wave reflection from a vertical permeable wave absorber," Coastal Engineering, vol. 7, no. 4, pp. 381-396, 1983.

[9] W. N. Seelig and J. P. Ahrens, "Wave reflection and energy dissipation by coastal structures," in Wave Forces on Inclined and Vertical Wall Structures, pp. 28-51, Task Committee on Forces on Inclined and Vertical Wall Structures, ASCE, Reston, VA, USA, 1995.

[10] J.-I. Lee, Y.-T. Kim, and S. Shin, "Experimental studies on wave interactions of partially perforated wall under obliquely incident waves," The Scientific World Journal, vol. 2014, Article ID 954174, 14 pages, 2014.

[11] R. L. Wiegel, Oceanographical Engineering, Vol. 72-75, Prentice-all, Inc., Upper Saddle River,NJ, USA, 1964.

[12] P. Boccotti, Wave Mechanics for Ocean Engineering, Elsevier Science, New York, NY, USA, 2000.

[13] J. W. Kamphuis, Introduction to Coastal Engineering andManagement, Advanced Series on Ocean Engineering, Vol. 16, World Scientific Publishing, Singapore, 2000.

[14] M. Mathiesen, Y. Goda, P. J. Hawkes et al., "Recommended practice for extreme wave analysis," Journal of Hydraulic Research, vol. 32, no. 6, pp. 803-814, 1994.

[15] P. Jonathan and K. Ewans, "Statistical modelling of extreme ocean environments for marine design: a review," Ocean Engineering, vol. 62, pp. 91-109, 2013.

[16] T. Takayama and Y. Kamiyama, "Diffraction of sea waves by rigid or cushion type breakwaters," Report of Port and Harbour Research Institute, vol. 16, no. 3, pp. 3-37, 1977.

[17] L. H. Holthuijsen, A. Herman, and N. Booij, "Phasedecoupled refraction-diffraction for spectral wave models," Coastal Engineering, vol. 49, no. 4, pp. 291-305, 2003.

[18] A. Sulis and A. Annis, Extreme Wave Analysis at SARLUX Jetty, DICAAR Technical Report, Sarroch, Italy, 2014, in Italian.

[19] P. A. Madsen and O. R. Sørensen, "A new form of the Boussinesq equations with improved linear dispersion characteristics. Part 2: a slowly-varying bathymetry," Coastal Engineering, vol. 18, no. 3-4, pp. 183-204, 1992.

[20] M. B. Abott, P. A. Madsen, and O. R. Sorensen, Scientific Documentation of Mike21 BW-Boussinesq Wave Module MIKE by DHI, 2001.

[21] G. Diaz-Hernandez, J. L. Lara, and I. J. Losada, "Extended long wave hindcast inside port solutions to minimize resonance," Journal of Marine Science and Engineering, vol. 4, no. 1, p. 9, 2016. 


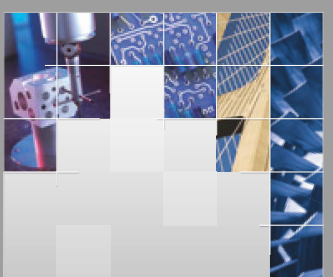

\section{Enfincering}
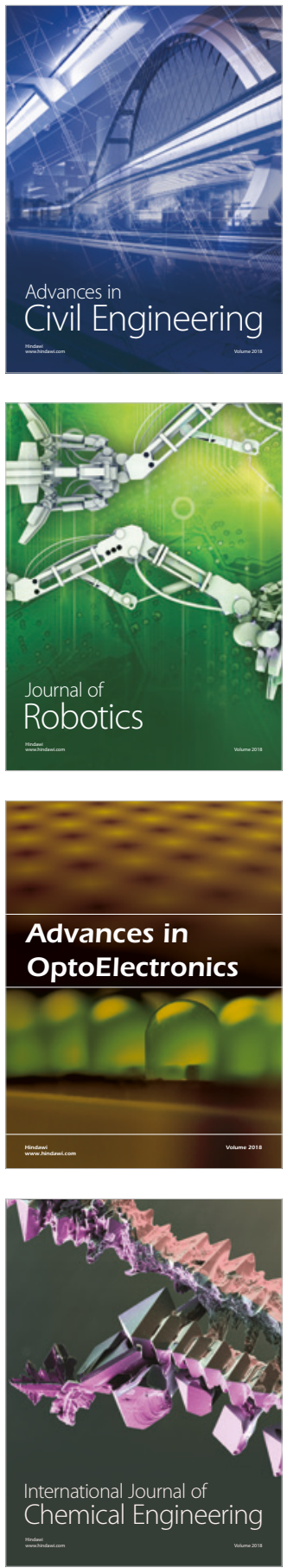

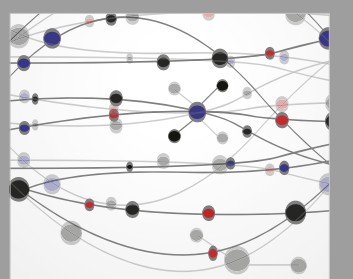

\section{Rotating \\ Machinery}

The Scientific World Journal

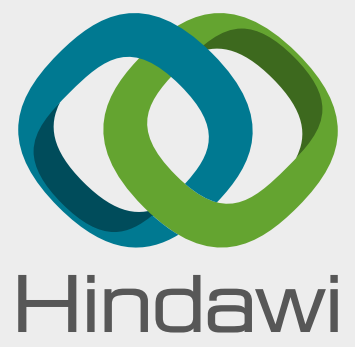

Submit your manuscripts at

www.hindawi.com
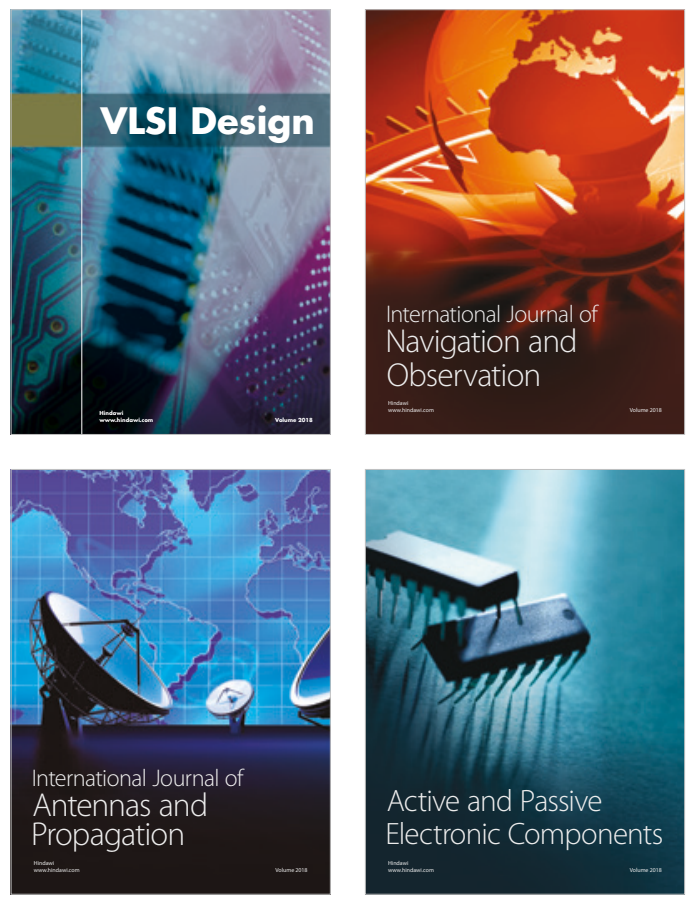
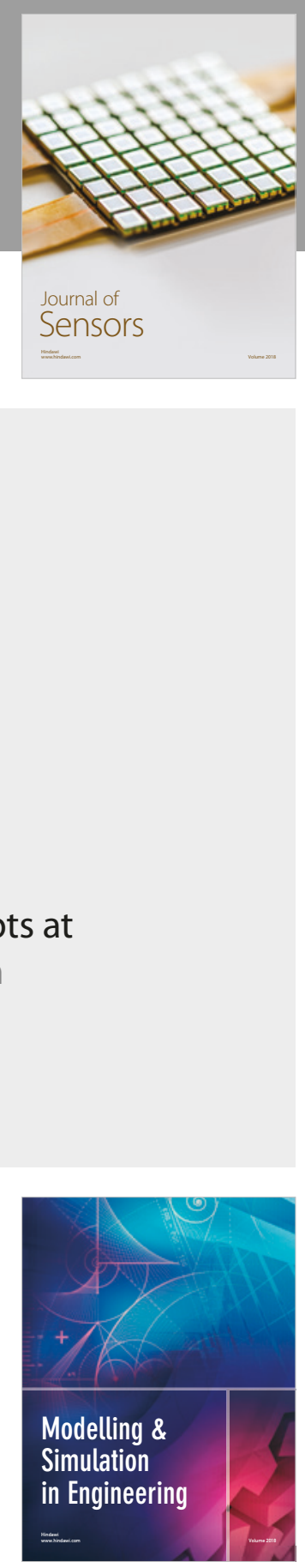

\section{Advances \\ Multimedia}
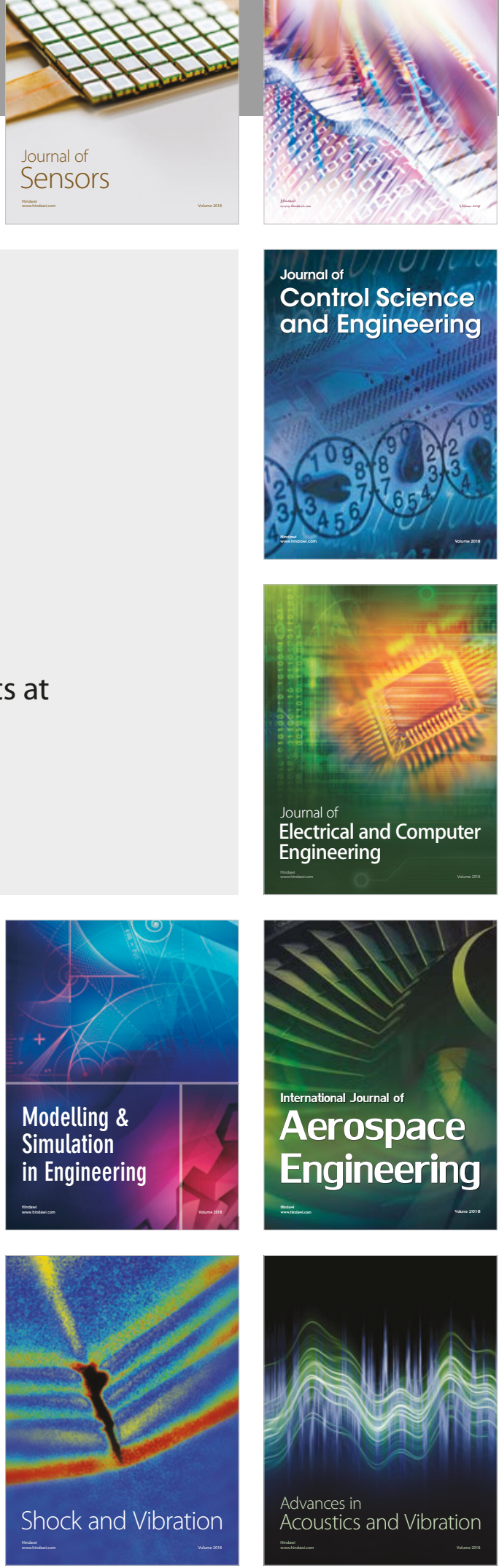